\title{
Obstetric outcomes at advanced maternal age
}

\author{
Valenti Eduardo Alberto, Laterra Cristina Marta, Gowdak Andrea Olga, Cohen Arazi Raul
}

Obstetrics and Gynaecology Department, Maternal and Childhood Hospital Ramón Sardá, Buenos Aires, Argentina

\section{Email address:}

eavalenti5@yahoo.com.ar (E. A. Valenti)

\section{To cite this article:}

Valenti Eduardo Alberto, Laterra Cristina Marta, Gowdak Andrea Olga, Cohen Arazi Raul. Obstetric Outcomes at Advanced Maternal Age. Journal of Gynecology and Obstetrics. Vol. 2, No. 1, 2014, pp. 7-11. doi: 10.11648/j.jgo.20140201.12

\begin{abstract}
Objective: To compare obstetric outcomes among women at advanced maternal age in relation to another group of 20 to 29 years. Methods: this is an observational descriptive study. Women of advanced maternal age were 40 and older at the first pregnant control $(\mathrm{N}=154)$. The control group were pregnant women between 20 and 29 years $(\mathrm{N}=3900)$. Odds ratio (CI 95\%), mean and standard deviation, median and Fisher exact test were used to compare. Results: The rate of chronic hypertension, preeclampsia, diabetes, and bleeding were higher in the study group when compared with the control group. The rate of caesarean sections (due to a great number of elective ones), preterm delivery $<37$ weeks and lower birth weight $(<$ $2500 \mathrm{~g}$ ) were also higher in the study group. Conclusion: women at advanced maternal age have an increased risk of adverse outcomes during pregnancy and delivery compared to pregnant women between 20 and 29 years. This electronic document is a "live" template. The various components of your paper [title, text, heads, etc.] are already defined on the style sheet, as illustrated by the portions given in this document.
\end{abstract}

Keywords: Advanced Maternal Age, Delayed Childbearing, Pregnancy Complications

\section{Introduction}

Currently there is a trend of delaying pregnancy and family planning. This delay can go as far as the sixth decade since today reproductive techniques allow it (1). As a result the birth rate in advanced maternal age increased and is also increasing all over the world $(2,3)$.

During the past three decades there was a delayed trend in getting pregnant in several industrialized countries. In Sweden the average maternal age for first pregnancy increased from 24.4 to 28.5 years between 1974 and 2001 . In the United States in the same period of time it increased from 21.4 to 24.9 years and in Japan from 25.6 to 28.0 between 1970 and 2000 .

The proportion of women who delivered after 40 years old also increased. In Sweden, the number of women among 40 to 44 years raised from 5.0 to 10.3 births per 1000 women; from 1980 to 2001 women over the age of 45 and older increased from 0.2 to 0.5 births per 1000 women. In England and Wales the number of women who delivered between 40 and 44 years increased from 5.1 to 8.4 and among those of age 45 and older from 0.3 to 0.5 births per 1000 women between 1991 and 2001. In the United Sates between 1981 and 1999 the number of women between 40 and 44 who delivered increased from 3.8 to 7.4 and from 0.2 to 0.4 in women of 45 and older $(4,5)$
The impact of advanced maternal age in perinatology is controversial. Some researchers suggest adverse outcomes (6) while others find only a mild increase in only a few obstetrics outcomes of this subgroup (7).

Lately society has accepted the pregnancy at advanced maternal age as a normal phenomenon in the lives of women, even though the fact that adverse outcomes present in the mother and the fetus are more common than in younger women. We do not know the etiology related to this problem yet.

In the past years advanced maternal age was defined after the age of 35 but now, in several countries, this group is considered to start at the fifth decade of life ( 40 years old) (8).

There are many papers related to pregnancies in women over 35 years, but only a few are referred to maternal age over $45(2,3,5)$. Some investigators believe that women over 45 are different with others risks and different measures of this risk (3).

It is certain that the risk of abortion is higher and fertility decreases due to the increase of age. Reproductive medicine has improved a lot to the solutions of fertility problems (5).

Some publications indicate an increased risk of 
hypertension, diabetes and cesarean delivery (9.10) in pregnant women at advanced maternal age.

Some investigators propose that the risk increase during the pregnancy and delivery after 40 years of age as well as the etiology of this phenomenon remain unknown yet $(2,3$, $5,9,10)$.

\section{Objectives}

1) To compare maternal and perinatal adverse outcomes among patients of 40 years and older with a sample of pregnant women between 20 and 29 years.

2) Determine the characteristics of the setting of women at advanced maternal age.

\section{Material and Methods}

This is an observational descriptive study. We compared women considered at advanced maternal age with a group of pregnant women who were considered at lower risk. Those women of 40 and older at the time of their first pregnancy control are defined as "advanced maternal age" (study group). The control group of patients between the age of 20 and 29 were considered less frequently associated to high perinatal risk.

Data collection was performed using the Perinatal Information System (SIP), from 1 January to 31 December 2009 and all births performed at the Hospital Materno Infantil Ramón Sarda (HMIRS) were recorded.

The variables taken into account in both groups were: maternal age, marital status, level of education (primary or secondary), number of previous pregnancies, number of previous vaginal deliveries, number of previous cesarean sections, chronic hypertension, preeclampsia, eclampsia, heart disease, diabetes, urinary infection, intrauterine growth restriction (IUGR), preterm labor, bleeding during pregnancy, premature rupture of membranes (PROM), postpartum infection, postpartum hemorrhage, existence of prenatal care, prenatal care during the 1 st. trimester, type of onset of labor (spontaneous or induced), type of delivery, ROM over 18 hours from birth, preterm delivery less than 37 , less than 34 and less than 32 weeks of gestational age at birth, Apgar Score after the first minute and after 5 minutes, birth weight, fetal and perinatal deaths.

The statistical analysis between the two groups and with the different variables were made using odds ratio with confidence interval $95 \%$ accordingly.

The mean and the standard deviation were used in continuous variables and median were used in the asymmetric distributions. With some variables, due to the small number of cases we used Fisher's exact test.

\section{Results}

During the study period 7325 women gave birth in the HMIRS, $154(2.1 \%)$ of them were at least 40 years old at the first visit during pregnancy.
The demographic and obstetric characteristics are shown in Table 1 . In the study group $50 \%$ were 40 or 41 years old, $50 \%$ had had 4 previous pregnancies, $7.1 \%$ were nulliparous and $31.7 \%$ had had cesarean sections.

Gestational age at birth, educational level and birth weight were similar in both groups. We found a low rate of single women in the study group (18.1\% vs. $35.7 \%)$ compared with the control group.

Outcomes during pregnancy are shown in table 2. The frequency of chronic hypertension, preeclampsia, diabetes, and bleeding were higher in the study group when compared with the control group.

In the group of advanced maternal age findings showed one women with heart disease and no one with eclampsia, therefore we could not use the OR but we applied the Fisher's exact test analysis. We did not find significant statistical differences with the control group.

Table 1. Demographic and obstetric characteristics for the study and control groups.

\begin{tabular}{|c|c|c|}
\hline & $\begin{array}{c}20 \text { a } 29 \text { years } \\
\qquad N=3900\end{array}$ & $\begin{array}{l}40 \text { years and older } \\
\qquad \mathrm{N}=154\end{array}$ \\
\hline \multicolumn{3}{|c|}{ MATERNAL AGE (years) } \\
\hline Mean \pm SD & $24.0 \pm 2.8$ & $41.3 \pm 1.5$ \\
\hline Median & 24 & 41 \\
\hline \multicolumn{3}{|l|}{ MARITAL STATUS } \\
\hline Single & $1392(35.7 \%)$ & $28(18.1 \%)$ \\
\hline \multicolumn{3}{|c|}{ EDUCATIONAL LEVEL } \\
\hline $\begin{array}{l}\text { Primary and/or } \\
\text { Secondary (high } \\
\text { school) }\end{array}$ & $3720(95.4 \%)$ & $147(95.9 \%)$ \\
\hline \multicolumn{3}{|c|}{ PREVIOUS GESTATIONS } \\
\hline Mean & 1.17 & 4.17 \\
\hline Median & 1 & 4 \\
\hline \multicolumn{3}{|c|}{ GEST. AGE AT BIRTH (weeks) } \\
\hline Mean \pm SD & $38.8 \pm 1.9$ & $38.5 \pm 1.9$ \\
\hline Median & 39 & 39 \\
\hline \multicolumn{3}{|l|}{ BIRTH WEIGHT (g) } \\
\hline Mean \pm SD & $3310.4 \pm 582.0$ & $3263.6 \pm 698.8$ \\
\hline \multicolumn{3}{|l|}{ PARITY } \\
\hline Nulliparity & $1800(46.2 \%)$ & $11(7.1 \%)$ \\
\hline $\begin{array}{l}\text { Multiparity (>3 } \\
\text { vaginal deliveries) }\end{array}$ & $76(1.9 \%)$ & $66(42.9 \%)$ \\
\hline \multicolumn{3}{|c|}{ PREVIOUS C- SECTIONS } \\
\hline One cesarean & $388(9.9 \%)$ & $26(16.9 \%)$ \\
\hline Two or more cesarean & $126(3.2 \%)$ & $23(14.8 \%)$ \\
\hline
\end{tabular}


Table 2. Pregnancy outcomes for study and control groups

\begin{tabular}{lcccccc}
\hline & \multicolumn{2}{c}{$\mathbf{2 0 - 2 9}$} & \multicolumn{2}{c}{$\mathbf{4 0}$ and older } & OR & CI 95\% \\
& $\mathbf{N}$ & $\mathbf{9}$ & $\mathbf{N}$ & $\mathbf{\%}$ & & $0.61-1.19$ \\
No pathologies found & 1958 & 50.2 & 71 & 46.1 & 0.85 & $7.19-47.25$ \\
Chronic hypertension & 13 & 0.3 & 9 & 5.8 & 18.56 & $1.02-4.59$ \\
Preeclampsia & 107 & 2.7 & 9 & 5.8 & 2.2 & Fisher=0.92 \\
Eclampsia & 2 & 0.1 & 0 & 0 & & Fisher=0.10 \\
Heart disease & 3 & 0.1 & 1 & 0.6 & & $3.48-10.50$ \\
Diabetes & 88 & 2.3 & 19 & 12.3 & 6.1 & $0.31-2.27$ \\
Urinary tract infection & 143 & 3.7 & 5 & 3.2 & 0.88 & $0.31-2.84$ \\
IUGR & 102 & 2.6 & 4 & 2.6 & 1.99 & $0.47-2.23$ \\
Preterm labor & 195 & 5.0 & 8 & 5.2 & 1.04 & $0.58-4.30$ \\
Multifetal gestations & 78 & 2.0 & 5 & 3.2 & 1.64 & $1.08-8.05$ \\
Bleeding & 41 & 1.1 & 5 & 3.2 & 3.16 & $0.87-2.0$ \\
ROM & 608 & 15.6 & 30 & 19.5 & 1.31 & $0.44-1.18$ \\
No tetanus vaccine & 697 & 17.9 & 21 & 13.6 & 0.73 & $0.44-1.18$ \\
VDRL positive & 80 & 2.1 & 4 & 2.6 & 1.27 & $0.83-3.34$ \\
Prenatal care (PC) & 3500 & 89.7 & 144 & 93.5 & 1.65 & $0.72-1.91$ \\
First visit at $1^{\circ}$ trimester & 483 & 13.8 & 22 & 15.3 & 1.18 & \\
\hline
\end{tabular}

Table 3 shows the results related to labor and delivery.

Table 3. Delivery outcomes for study and control groups

\begin{tabular}{|c|c|c|c|c|c|c|}
\hline & \multicolumn{2}{|c|}{$20-29$} & \multicolumn{2}{|c|}{40 and older } & \multirow{2}{*}{ OR } & \multirow{2}{*}{ CI $95 \%$} \\
\hline & $\mathbf{N}$ & $\%$ & $\mathbf{N}$ & $\%$ & & \\
\hline Spontaneous onset & 2934 & 75.2 & 77 & 50.0 & 0.43 & $0.31-0.60$ \\
\hline Induction & 388 & 9.9 & 18 & 11.7 & 1.20 & $0.70-2.02$ \\
\hline Spontaneous delivery & 2846 & 73.0 & 85 & 55.2 & 0.42 & $0.30-0.59$ \\
\hline Vaginal delivery (spontaneous + instrumental) & 2982 & 76.5 & 85 & 55.2 & 0.38 & $0.27-0.53$ \\
\hline Cesarean section & 916 & 23.5 & 69 & 44.8 & 2.64 & $1.88-3.71$ \\
\hline Elective Cesarean section & 567 & 14.5 & 59 & 38.3 & 3.65 & $2.57-5.18$ \\
\hline Postpartum infection & 106 & 2.7 & 4 & 2.6 & & Fisher $=0.95$ \\
\hline Postpartum hemorrhage & 26 & 0.7 & 1 & 0.6 & & Fisher $=0.97$ \\
\hline Preterm delivery $<37 \mathrm{w}$. & 403 & 10.3 & 27 & 17.5 & 1.84 & $1.17-2.88$ \\
\hline Preterm delivery $<34 \mathrm{w}$. & 111 & 2.8 & 4 & 2.6 & & Fisher $=0.55$ \\
\hline Preterm delivery $<32 \mathrm{w}$. & 59 & 1.5 & 1 & 6.5 & & Fisher $=0.32$ \\
\hline $\mathrm{ROM}>18 \mathrm{hs}$ & 76 & 1.9 & 5 & 3.2 & & Fisher $=0.19$ \\
\hline 2 or more cesarean sections & 126 & 3.2 & 23 & 14.8 & 5.26 & $3.17-8.67$ \\
\hline Cesarean delivery with one previous cesarean & 201 & 51.8 & 17 & 65.3 & 1.76 & $0.72-4.38$ \\
\hline Fetal mortality & 13 & $3.3 \% \mathrm{o}$ & 2 & $13 \% \mathrm{o}$ & & Fisher $=0.10$ \\
\hline Perinatal mortality & 15 & $3.8 \% \mathrm{o}$ & 2 & $13 \% \mathrm{o}$ & & Fisher $=0.10$ \\
\hline
\end{tabular}

The frequency of caesarean sections was higher in the study group $(\mathrm{OR}=2.6495 \% \mathrm{CI} 1.88-3.71)$ due to a higher rate of elective caesarean sections $(\mathrm{OR}=3.6595 \% \mathrm{CI}$ 2.57-5.18) compared with the control group. The indication of 2 or more previous cesareans sections was stronger in the group of advanced maternal age women $(\mathrm{OR}=5.26 \mathrm{IC} 95 \%$

\subsection{7-8.67).}

Caesarean section occurred more frequently among women with one previous cesarean (OR $=1.76$ IC95\% $0.72-4.38$ ) but this difference was not significant in relation to the control group. 
Table 4. Neonatal outcomes

\begin{tabular}{|c|c|c|c|c|c|c|}
\hline & \multicolumn{2}{|c|}{$20-29$} & \multicolumn{2}{|c|}{40 and older } & \multirow{2}{*}{ OR } & \multirow{2}{*}{ CI 95\% } \\
\hline & $\mathbf{N}$ & $\%$ & $\mathbf{N}$ & $\%$ & & \\
\hline Apgar score 1st. minute $<4$ & 26 & 0.7 & 2 & 1.3 & & Fisher $=0.28$ \\
\hline Apgar score 1 st. minute $<7$ & 109 & 2.8 & 6 & 3.9 & 1.41 & $0.55-3.34$ \\
\hline Apgar score $5^{\text {th }} \cdot$ minute $<4$ & 12 & 0.3 & 0 & 0 & & \\
\hline Apgar score $5^{\text {th }} \cdot$ minute $<7$ & 31 & 0.8 & 0 & 0 & & \\
\hline Birth weight $<2500 \mathrm{~g}$ & 235 & 6.0 & 19 & 12.3 & 2.19 & $1.29-3.69$ \\
\hline
\end{tabular}

Fetal mortality and perinatal mortality were higher in the group of older women.

Table 4 shows neonatal outcomes associated to the Apgar Score 1st. and 5th. Minute and the frequency of low birth weight $(<2500 \mathrm{~g})$, which is higher in the study group compared with the control group (OR $=2.19$ IC95\% 1.29-3.69).

\section{Discussion}

In the last three decades of family planning there has been a shift in the age of childbearing to the fifth decade of life of women $(2,5)$. Pregnancy after age 40 has special characteristics that turn these women into a high risk setting in diagnosis and treatment. However we did not find important evidence in the international literature available.

The data is inconsistent and it may be related to the limitations of available studies including small sample size, comparison of different maternal age groups, different social background of patients and no uniform definitions.

Some studies show the results of women over 39 years of age and find association to higher frequency of chronic maternal diseases (hypertension and diabetes) and medical complications of pregnancy (gestational diabetes and preeclampsia), increased frequency of cesarean postpartum hemorrhage, postpartum fever, blood transfusions and prolonged hospitalization, higher rate of preterm birth, low birth weight and finally higher admission to ICU. These results worsened with increasing maternal age (3,11-13).

In our study the prevalence of women aged 40 years or more was $2.1 \%$, but the frequency of complications in pregnancy in this group is increased significantly. As we expected the frequency of nulliparity was only $7.1 \%$ which means that many of these women chose to give birth again after age 40 . This was published by other researchers although some of them found increases in the rate of nulliparity (3).

In the present study we found significant increase in chronic medical complications such as chronic hypertension and diabetes as well as acute complications like preeclampsia and bleeding during pregnancy. These conditions may explain the increase in indicated preterm delivery (14).

The increase in multiple pregnancies was higher in the study group, this difference was not significant as shown by others authors (3.5). The cause may be due to age-related multiple ovulations but in our sample assisted reproduction is very rare.

Extreme prematurity (less than 32 weeks) was not higher in the study group while the number of births under 37 weeks was significantly higher.

We did not find statistically significant increase in urinary tract infection, IUGR, preterm labor or ROM in the study group.

Prenatal care attention, the early onset of prenatal care, tetanus vaccination and the existence of positive VDRL showed no differences between groups.

The onset of labor was similar in both groups. About 50\% of women had a cesarean section. We saw an important influence of elective indication, and within these the indication for two or more previous cesarean sections was very strong.

A cesarean section was made in $65 \%$ of women with a prior cesarean. This is higher compared to the control group that had a rate of cesarean delivery of $51 \%$. There are speculations about, if there is a lightness to indicate the caesarean section in this age group (5). This lightness increases after age 40, primiparity, and treatment of infertility (2).

Some investigators suggested a higher frequency of fetal and neonatal death in this group (5).

In our study there was increased fetal mortality and perinatal mortality in older women. Puerperal complications reported by others (3) such as postpartum fever, postpartum hemorrhage and prolonged hospitalization were not more frequent in our study.

Neonatal depression at birth showed no differences among groups and we found statistical significant difference in the increased low birthweight babies in the group of older women.

During the $20^{\text {th }}$ century it was common being pregnant and giving birth at the advanced maternal age. In that time women began early with their first pregnancy and finished late with their last pregnancy often after 40 years old (5). Today women are using the latter part of their lives to have a child and this trend is being more common as time goes by.

\subsection{Advantages}

The study shows an increased risk of conditions related to pregnancy and delivery which indicates that planning should encourage these pregnancies to achieve early prenatal care and appropriate following. Specially among our population 
because the prevalence of multiparity is high in this age group.

It should promote the creation of study groups and follow-up schemes at hospital level to increase knowledge and research on these pregnancies.

These results should be taken into consideration by patients and physicians when it is necessary to plan a pregnancy and thus contribute to better obstetric following and prevention of possible complications during pregnancy and delivery.

\subsection{Limitations}

We excluded pregnancies that ended before viability (less than 24 weeks) because we wanted perinatal outcomes. There is a higher incidence of abortions in this age group.

We have neither long time nor short time follow up history of mothers and children of these groups of advanced maternal age.

We had no reliable information about smoking and alcohol consumption and these are habits that influence on perinatal outcome.

The stratified analysis by socioeconomic status would be useful.

\subsection{Strengths}

It should be implemented the preconception care in advanced maternal age to improve clinical conditions and to prevent infectious diseases and congenital anomalies. For example: folic acid intake, blood glucose level, treatment of hypertension, cervical and vaginal cultures. If preconception care is not possible very early prenatal care should be promoted to reach similar effects.

In addition it would be best to perform special task groups with multidisciplinary specialists to improve preventive actions and follow up of advanced maternal age patients.

\subsection{Weaknesses}

It is a retrospective study of only one year (2009). We did not study maternal habits like alcohol, smoking and other licit drugs as well as illicit drugs due to unreliable registries.

We did not have the follow up of mothers or children because we are starting new clinical schemes.

We did not consider for analysis the different social and economic status related to income groups.

We did not study abortions because we wanted to know only perinatal outcomes.

It is necessary to make a prospective study including the follow up of both mothers and children to observe the clinical and the psychological consequences of advanced maternal age. It will be useful to study first and second trimester complications because there are a lot of fertilization treatments and women have usually been prescribed with progesterone, estrogens and gonadotropins. Definitely we need to separate groups according to their social income because this is directly related to medical care accessibility.

\section{References}

[1] Kreig SA, Henne MB and Westphal LM. Obstetric outcomes in donor oocyte pregnancies compared with advanced maternal age in in vitro fertilization pregnancies. Fertil Steril 2008; 90: 65-70.

[2] Bianco A, Stone J, Lynch L, Lapinski, Berkowitz G and Berkowitz RL. Pregnancy outcome at age 40 and older. Obstet Gynecol 1996; 87: 917-22.

[3] Yogev Y, Melamed N, Bardin R, Tenenbaum-Gavish K, Ben-Shitrit G and Ben-Haroush A. Pregnancy outcome at extremely advanced maternal age. Am J Obstet Gynecol 2010; 203: 558.e1-7.

[4] American College of Obstetricians and Gynecologists (ACOG). Age-Related Fertility Decline. ACOG Committee Opinion, number 413, august 2008 .

[5] Jacobsson B, Ladfors L and Milsom I. Advanced Maternal Age and Adverse Perinatal Outcome Obstet Gynecol 2004; 104: 727-33. (LEVEL OF EVIDENCE: II-3)

[6] Delpisheh A, Brabin L, Attia E and Brabin BJ. Pregnancy Late in Life: A Hospital-Based Study of Birth Outcomes. J Womens Health (Larchmt). 2008; 17(6): 965-970.

[7] Callaway LK, Lust K, McIntyre HD. Pregnancy outcomes in women of very advanced maternal age. Aust N Z J Obstet Gynaecol. 2005; 45(1): 12-6.

[8] Gilbert WM, Nesbitt TS, Danielsen B. Childbearing beyond age 40: pregnancy outcome in 24,032 cases. Obstet Gynecol 1999; 93: $9-14$.

[9] Balducci J, Staud J, Curtis Bay R, Williamson KJ. Coonrod DV. Maternal and Perinatal Outcomes of Women With Advanced Maternal Age. Obstet Gynecol 2005;105 (Supplement N4): 1115-6.

[10] Berkowitz GS, Skovron ML, Lapinski RH and Berkowitz RL Delayed childbearing and the outcome of pregnancy. N Engl J Med 1990; 322:659-64.

[11] Cleary-Goldman J, Malone FD, Vidaver J, Ball RH, Nyberg DA, Comstock $\mathrm{CH}$ et al. Impact of Maternal Age on Obstetric Outcome. Obstetrics and Gynecology, 2005; 105 (5): 983-90.

[12] Joseph K S, Allen AC, Dodds L, Turner LA, Scott H and Liston R. The Perinatal Effects of Delayed Childbearing. Obstetrics and Gynecology, 2005; 105 (6): 1410-8.

[13] Usta IM and Nassar AH. Advanced Maternal Age. Part I: Obstetric Complications. American Journal of Perinatology 2008; 25 (8): 521-534.

[14] Khoshnood B, Bouvier-Colle MH, Leridon H and Blondel B. Impact of advanced maternal age on fecundity and women's and children's health, Journal de Gynecologie, Obstetrique et Biologie de la Reproduction. 2008; 37(8):733-47. 